\title{
Estimating clutch frequency in the sea turtle Dermochelys coriacea using stopover duration
}

\author{
Philippe Rivalan ${ }^{1, *}$, Roger Pradel $^{2}$, Rémi Choquet ${ }^{2}$, Marc Girondot $^{1}$, \\ Anne-Caroline Prévot-Julliard ${ }^{1}$
}

${ }^{1}$ Laboratoire d'Écologie, Systématique et Évolution, UMR 8079 CNRS, ENGREF et Université Paris-Sud XI, 91405 Orsay Cedex, France

${ }^{2}$ Centre d'Ecologie Fonctionnelle et Evolutive, CNRS UMR 5175, 1919 route de Mende, 34293 Montpellier Cedex 5, France

\begin{abstract}
When direct counts are not possible, relative population size indices, based on animal activity (e.g. number of tracks, burrows, feces, calls per unit area), are sometimes the only tools available to investigate population size variations over time. In sea turtles, the number of clutches laid on a nesting beach in a particular season is commonly used as a relative index of population density. The factor of proportionality that links the relative index and population density is the number of clutches annually laid per female per season or clutch frequency. At Awa:la-Ya:lima:po Beach, French Guiana (South America), we estimated clutch frequency in the sea turtle Dermochelys coriacea using capture-recapture monitoring over an 8 yr period (1995 to 2003, 1997 excluded). We compared 2 methods: (1) Estimated Clutch Frequency (ECF), where Observed Clutch Frequency (OCF) was corrected by taking account for intermediate missed nests, and (2) Total Clutch Frequency (TCF) derived from recent advances in capture-recapture methodologies that were initially developed to estimate stopover duration in migratory animals. Compared to the first method, the latter enabled estimation of the time spent before first capture and after the last capture, as well as the capture probability. Mean annual clutch frequency derived from stopover duration was considerably higher than ECF (respectively 2.38 and 7.01 clutches female $\mathrm{e}^{-1} \mathrm{yr}^{-1}$ ). In nesting sites where survey effort is low and variable over years, using capture-recapture data analysis might enhance the reliability of conclusions about population size in marine turtles.
\end{abstract}

KEY WORDS: Relative index $\cdot$ Population size $\cdot$ Survey effort $\cdot$ Stopover duration $\cdot$ Observed Clutch Frequency · Estimated Clutch Frequency · Total Clutch Frequency · Leatherback sea turtles · Dermochelys coriacea

- Resale or republication not permitted without written consent of the publisher

\section{INTRODUCTION}

When population density cannot be estimated from direct counts, relative measures or density indices based on animal activity signs (e.g. number of tracks, burrows, feces, or calls per unit area) are commonly used in wildlife studies, particularly in studies with terrestrial vertebrates (Thompson et al. 1989, Becker et al. 1998, Schwarz \& Seber 1999, Wilson \& Delahay 2000, Altrichter \& Boaglio 2004). These indices assume a fixed level of search effort that allows the researcher to locate the same proportion of the population. When no adjustment for variable search effort, or for variations in environmental parameters, is possible, the assumption is that the relative index is proportional to population density and that the proportionality factor is constant over time (Seber 1982, Schwarz \& Seber 1999).

Although sea turtles are predominantly a marine species, estimations of abundance are based on activity signs recorded in terrestrial habitats where females aggregate to lay eggs during nesting season. In marine turtles that feed and nest in the northern hemisphere, nesting activity mainly occurs between early summer and fall. Females crawl onto the tropical and sub- 
tropical beaches mostly between dusk and dawn, excavate a nest in the sand to deposit their clutch, and then return to the sea. Each individual repeats this process several times a year (Miller 1996). This period of egg deposition is often the only occasion when a substantial part of a sea turtle population is easily accessible for sampling. It therefore presents an important opportunity for studying population dynamics of adult female sea turtles. Many studies have used the total number of clutches laid in a particular season as a relative index of reproductive population size (Gerrodette \& Talylor 1999, Schroeder \& Murphy 1999, Broderick et al. 2002, Troëng \& Rankin 2005). The proportionality factor is the number of clutches female ${ }^{-1} \mathrm{yr}^{-1}$ (also called clutch frequency). Therefore, without information on clutch frequency, a change in the number of nests recorded may be attributed to a change in the number of females nesting, although it may simply reflect annual variation in reproductive output.

Clutch frequency in sea turtles is assessed using capture-recapture (CR) data collected on nesting beaches. For CR sampling, nesting females are individually tracked over time using external metal tags (Limpus 1992, Bjorndal et al. 1996) or internal Passive Integrative Transponders (PIT; Dutton \& McDonald 1994, McDonald \& Dutton 1996, Godley et al. 1999). Tagging and re-sighting are carried out when female sea turtles come ashore for nesting. The minimal information related to clutch frequency gathered from beach monitoring is the number of clutches recorded for each female, referred to as Observed Clutch Frequency (OCF; Frazer \& Richardson 1985). However, if all nesting events are not exhaustively observed, OCF can underestimate true clutch frequency (Frazer \& Richardson 1985, Frazer \& Richardson 1986, Johnson \& Ehrhart 1996, Broderick et al. 2002). Frazer \& Richardson (1985) proposed a corrected estimator of OCF to account for bias due to low survey effort. This value, referred to as Estimated Clutch Frequency (ECF), evaluates the number of missed clutches between the first and the last observation (Frazer \& Richardson 1985). Because of year-to-year variations in time spent before first capture, time spent after last capture and resighting effort, it is unclear whether inter-annual variations in ECF (Frazer \& Richardson 1985, Frazer \& Richardson 1986, Johnson \& Ehrhart 1996) really reflect variations in clutch frequency. Moreover, ECF is based only on turtles observed at least twice and may not be representative of the entire population.

Reliable estimations of clutch frequency are required to derive the annual number of breeding females from nest counts. Schaub et al. (2001) developed a new approach for estimating the stopover duration (i.e. total time an animal is present in the sampling area) in migratory birds using $\mathrm{CR}$ monitoring. Relying on recent advances in CR data analysis (for modelling of survival see Lebreton et al. 1992), this method estimates the time the animal has spent at the sampling place before and after capture. In the context of sea turtles, this method is of interest for estimating clutch frequency. Indeed, by properly estimating the interval between 2 clutches, the number of clutches female ${ }^{-1}$ $\mathrm{yr}^{-1}$ can be estimated from the stopover duration.

The study reported in this paper was based on Awa:la-Ya:lima:po beach, western French Guiana (South America), one of the largest remaining nesting grounds for the critically endangered leatherback sea turtle Dermochelys coriacea (Spotila et al. 1996, Hilton-Taylor et al. 2002). Using CR data, we first estimated OCF and ECF as proposed by Frazer \& Richardson (1985). We then estimated clutch frequency based on stopover duration (Schaub et al. 2001). finally, we compared the number of females breeding annually on this nesting beach (derived from nest counts) when computations were based on ECF or on stopover duration.

\section{MATERIALS AND METHODS}

Natural history of leatherback sea turtles. The leatherback sea turtle is a pelagic species that migrates between foraging and nesting grounds (Miller 1996). The foraging distribution of the leatherbacks encompasses tropical, temperate and sub-polar waters (Girondot \& Fretey 1996, James 2000, James \& Herman 2001, Hays et al. 2004), whereas nesting activities are limited to tropical and subtropical areas (Miller 1996, Spotila et al. 1996). Within a nesting season, females lay up to 13 nests (Girondot \& Fretey 1996). The interval between 2 successive clutches varies from 6 to 12 d (Girondot \& Fretey 1996). Although marine turtles generally display fidelity to their nesting beach (Allard et al. 1994), leatherbacks sometimes make excursions to nearby beaches (Spotila et al. 1996, Hilterman \& Goverse 2003, Rivalan 2004). After depositing their last clutch, females leave the nesting ground and travel back to the foraging ground (Ferraroli et al. 2002).

Data collection. The present study took place in the Maroni River estuary, at the border between French Guiana and Suriname (Fig. 1). The beach Awa:laYa:lima:po, located on the eastern side of the estuary, is the largest nesting beach in the region (Spotila et al. 1996). However, other beaches close by also host nesting leatherbacks, especially on the western side of the Maroni River (e.g. Babusanti, Kolukubo beaches; Fig. 1). Because observations showed that some females nest on both sides of the Maroni River (Hilterman \& Goverse 2003), females from French Guiana 


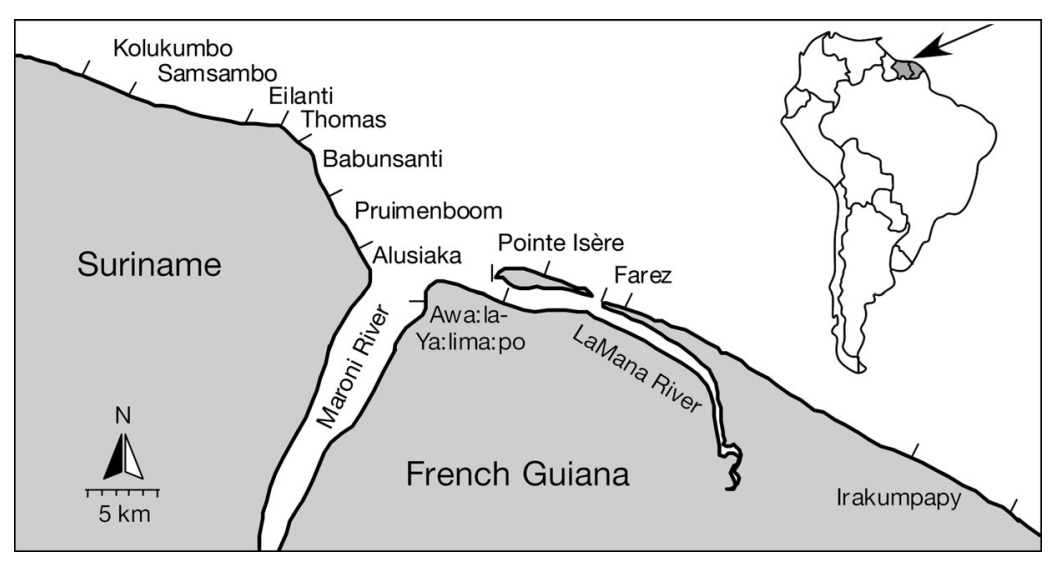

Fig. 1. Dermochelys coriacea. Major nesting beaches around the Maroni River estuary. Capture-recapture data were collected on Awa:la-Ya:lima:po beach, on the eastern side of the estuary

and females from Suriname were generally assumed to belong to the same population.

Since 1987, individual identification of breeding females by tagging and re-sighting has been performed using 2 types of markers. From 1987 to 1994 (1989 excluded) and in 1997, females were tagged with a self-piercing, numbered metal tag on the left rear flipper (Girondot \& Fretey 1996). From 1995 to 2003 (1997 excluded), tagging was performed by injecting an encoded microchip (i.e. PIT tags) into the right shoulder muscles of the turtle (McDonald \& Dutton 1996). Each year, from March-April to mid-August, the beach was patrolled at night from $2 \mathrm{~h}$ before until $2 \mathrm{~h}$ after the high tide (Girondot \& Fretey 1996). Nesting females encountered during patrols were scanned for tags. If a tag was present, their identity was recorded. If no tag was present, a PIT tag was injected into the right shoulder of the turtle.

Because a high tag-loss rate occurs with Monel tags (Rivalan et al. 2005), we limited our analyses to CR data gathered from PIT tags (i.e. from 1995 to 2003, 1997 excluded). Unsuccessful detections of PIT tags have been reported in flatback (Parmenter 1993), green (Godley et al. 1999) and loggerhead turtles (Godley et al. 1999). However, Dutton \& Dutton (1994) did not find any evidence of intra-seasonal PIT tag loss in leatherback sea turtles nesting in Sandy Point National Wildlife Refuge on St. Croix, US Virgin
Islands. We therefore assumed that PIT tags were not lost within nesting seasons in leatherbacks nesting in French Guiana. The total number of females observed per nesting season and the mean number of clutches per female (OCF; Frazer \& Richardson 1985) on this beach are reported in Table 1.

In sea turtles, not all nesting attempts result in a successful egg-laying. Failures generally occur when females are disturbed during the nesting process (Schroeder \& Murphy 1999). The proportion of non-nesting emergences can vary over years with beach quality due to rain, debris or tourist activity. When a female was observed more than once within a $3 \mathrm{~d}$ period, we assumed that she failed to nest at the time of the first observation. In order to conserve only successful nesting attempts, we discarded the first observation and kept only the last one.

Estimation of ECF. ECF is the number of clutches that a turtle is believed to have deposited (Frazer \& Richardson 1985, Johnson \& Ehrhart 1996). To compute ECF, we followed Frazer \& Richardson's (1985) method. ECF values were based on the number of days between observations (i.e. inter-nesting interval). The mean inter-nesting interval for leatherback turtles at Awa:la-Ya:lima:po beach was $9.8 \mathrm{~d}$ (Fretey \& Girondot 1989). The number of nests added to each turtle's record was calculated by dividing the number of days a female spent at large by 9.8 (if longer than $19 \mathrm{~d}$ ). For turtles where intervals from 15 to $18 \mathrm{~d}$ occurred between observed nesting events, it was assumed that 1 clutch was deposited during this time (Frazer \& Richardson 1985, Johnson \& Ehrhart 1996). Following the same method, we also computed ECF for females seen more than once, in order to minimize bias due to one-time nesters.

Modelling clutch frequency. A limitation of ECF is that it neglects the time an animal spends at the nesting area before the first and after the last observations. To correct this bias, we used new advances in CR data analyses to estimate the total duration an animal is present in the sampling area (Schaub et al. 2001). This

Table 1. Dermochelys coriacea. Annual number of observations and mean Observed Clutch Frequency (OCF) of leatherback sea turtles in Awa:la-Ya:lima:po from 1995 to 2003 (1997 excluded)

\begin{tabular}{|lcccccccc|}
\hline & 1995 & 1996 & 1998 & 1999 & 2000 & 2001 & 2002 & 2003 \\
\hline No. observations & 248 & 208 & 1123 & 1343 & 1702 & 2311 & 1272 \\
Mean OCF & 1.16 & 1.11 & 1.64 & 1.59 & 1.39 & 2.26 & 2.52 & 1372 \\
(Range) & $(1-6)$ & $(1-7)$ & $(1-6)$ & $(1-6)$ & $(1-6)$ & $(1-11)$ & $(1-9)$ & $(1-9)$ \\
\hline
\end{tabular}




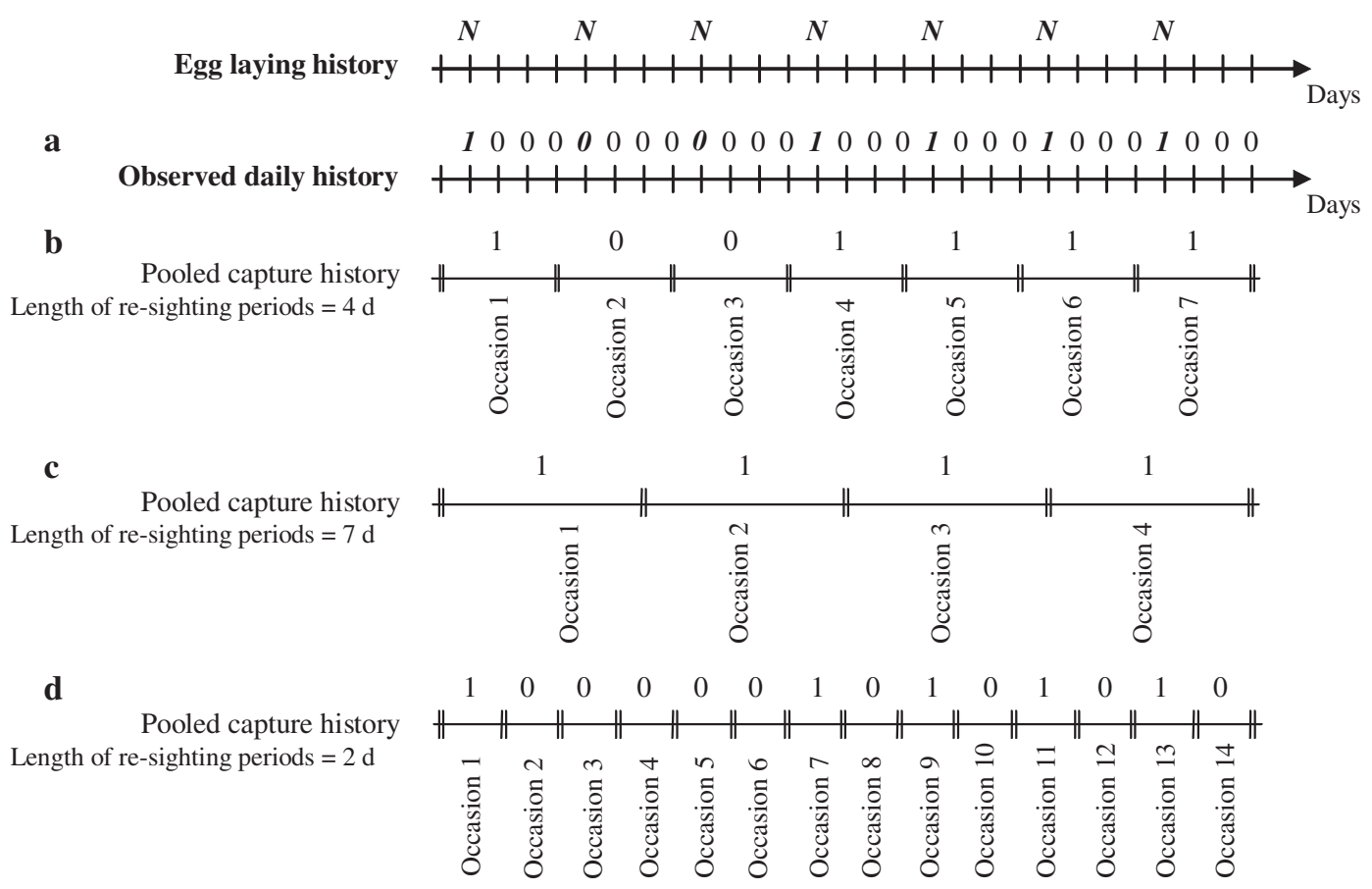

Fig. 2. Effect of length of re-sighting periods on capture histories on a hypothetical turtle that nests every $4 \mathrm{~d}$, which is observed with a capture probability $\mathrm{p}=0.7$. $N$ : egg laying event. (a) Observed daily history: ' 1 ' and ' 0 ', respectively, represent an observation and a non-observation (italic indicates days when animal nested). (b) Relevant re-sighting periods give good representation of the real nesting behavior. (c) A too large re-sighting pooling period led to an artificial excess of successful observations in capture histories = trap-happiness. (d) A too small re-sighting pooling period led to an excess in non-observations in capture histories $=$ trap-shyness

value, termed total stopover duration, is expressed in number of re-sighting periods (Schaub et al. 2001). By adequately calibrating re-sighting periods, such as only one clutch is laid per re-sighting period, the total stopover duration directly approximates the total önumber of clutches female $\mathrm{yr}^{-1} \mathrm{yr}^{-1}$. Referring to original terminology related to stopover (i.e. minimum stopover vs. total stopover; Schaub et al. 2001), the total number of clutches female ${ }^{-1} \mathrm{yr}^{-1}$ derived from stopover duration will hereafter be referred to as Total Clutch Frequency (TCF).

Assumptions underlying $\boldsymbol{C R}$ models: $\mathrm{CR}$ models rely on several assumptions regarding independence of individuals and homogeneity of recapture or survival probability regardless of previous capture history (Lebreton et al. 1992). Violations of these assumptions may necessitate adjustments to the model structure (e.g. Lebreton et al. 1992) and/or data structure (e.g. Pradel 1993). Previous survival analyses based on CR data from Awa:la-Ya:lima:po beach indicated that several assumptions underlying CR models were not met (M. Girondot unpubl. data, Rivalan 2004). Infidelity to the nesting site in leatherbacks induces the occurrence of transients on Awa:la-Ya:lima:po beach (i.e. turtles only seen once a year; Pradel et al. 1997). The appearance of these visitors, originating from the nearby nesting beaches, may lead to biased estimates of local sur- vival rate (Pradel et al. 1997). Furthermore, daily CR data structure violated the assumption of homogeneity in capture among individuals. As aforementioned, females are available for detection only when they lay

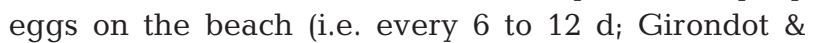
Fretey 1996). Therefore, a turtle that nested on Day $d$ (and was thus potentially observable) has a lower probability to nest on Day $d+1$ (and thus to be observable) than a turtle that nested before Day $d$. However, this bias can be eliminated if daily CR data are relevantly pooled (see next subsection).

Definition of relevant resighting periods: In a daily observation regime, the lag time between 2 successive clutches induces sequences of one observable state followed by several non-observable states (Fig. 2a). This is known as a trap-shyness effect (Fig. 2a; Pradel 1993), violates the assumption of capture homogeneity (i.e. each individual does not have the same resighting probability at a given occasion). We thus pooled daily observations into adequate time periods during which females nested only once (Fig. 2b,c). We assessed the most relevant duration of time periods by running Test 2.CT and $N(0,1)$ statistics (Pradel 1993) on rearranged data sets with time periods from 6 (i.e. minimal time required to produce 2 successive clutches in marine turtles; Owens 1980) to $12 \mathrm{~d}$. Test 2.CT estimates the probability of trap-dependence in the data set whereas 
the $\mathrm{N}(0,1)$ statistic predicts the direction of the detected trap-effect (i.e. $\mathrm{N}(0,1)<0=$ trap-happiness, $\mathrm{N}(0,1)>0$ = trap-shyness, Pradel 1993). A long timeperiod would lead to an increased probability of resighting an animal already observed ('trap-happiness'; Fig. 2c), whereas a small time-period would lead to a decreased probability of re-sighting already observed animals ('trap-shyness'; Fig. 2d).

Defining relevant re-sighting periods has immediate consequences for interpretation of stopover duration. As previously mentioned, stopover duration expresses the number of re-sighting periods an animal is present in the sampling area. Since Test 2.CT selects the time period in which a female is seen only once, the stopover duration directly approximates total clutch frequency (TCF).

Computation of stopover durations: Estimation of the total stopover duration was performed from CR data using SODA software (Choquet et al. 2000, Schaub et al. 2001). Minimum stopover was calculated as the number of capture occasions between the first and last capture (or re-sighting) for a given turtle. However, not all individuals at the sampling area on a given occasion are captured. A turtle may have arrived before its first capture and may have left the study area after its last capture. Individual capture histories can be analyzed using classical CR methods. This allows estimation of the following parameters: (1) capture probability on a given occasion; (2) local survival probability (Lebreton et al. 1992), which is 1 minus the emigration probability-from this the duration of stay after an occasion of capture can be estimated; (3) local seniority probability (proportion of the population that was already present prior to the first capture, Pradel 1996) which is 1 minus the immigration probabilityfrom this the duration of stay before an occasion capture can be computed. The sum of both durations is an estimate of the expected stopover duration of animals present on that capture occasion (for further details, see Schaub et al. 2001).

Once the time periods for pooling data were assessed, we followed Schaub et al.'s (2001) recommendations for estimating stopover durations. First, we selected survival and recruitment models. To take transients into account, we included a distinct parameter in the survival model to account for survival of individuals immediately after first capture (Pradel et al. 1997). Hereafter, models that account for transients in survival modelling are denoted with the subscript $\tau$ which represents transients.

We used the Akaike's Information Criterion corrected for small samples size (AICc) to select the most parsimonious model for the data. The model with the lowest AICc was selected (Akaike 1974, Lebreton et al. 1992). When the difference in $\mathrm{AICC}(\triangle \mathrm{AICC})$ between
2 nested models is lower than 2 , the 2 models equally describe variation in the data (Lebreton et al. 1992). In this case, when the constrained model had a higher AICc than the general one, we used the Likelihood Ratio (LR) test to help in model selection.

We then estimated stopover duration using SODA software (Schaub et al. 2001) with the MSURGE selected models. Confidence intervals of total stopover duration were obtained using a non-parametric bootstrap (1000 iterations) on individual capture histories (Schaub et al. 2001).

Inter-annual variations in the annual mean stopover durations were tested by performing repeated measures ANOVAs using SAS (SAS Institute). Repeated measures ANOVAs were performed using the stopover durations generated by bootstrap resampling. We used 20 turtles $\mathrm{yr}^{-1}$ to keep the test conservative with respect to the number of field observations.

\section{RESULTS}

\section{Calculating ECF}

ECF for all the nesting females gave values ranging from $1.32\left(\mathrm{SE}=5 \times 10^{-3}\right)$ in 1996 to $3.63(\mathrm{SE}=3 \times$ $10^{-3}$ ) in 2002 (Fig. 3), with a mean ECF of 2.38 (SE $=3$ $\left.\times 10^{-3}\right)$. ECF varied significantly among years $(F=$ 118.65, df $=8, \mathrm{p}<0.01$ ), with a significant increasing trend $(F=546.67$, df $=1, \mathrm{p}<0.01) . \mathrm{ECF}_{\mathrm{r}}$, the estimated clutch frequency for females seen more than once, followed the same pattern as ECF estimated for all females (Fig. 3). As expected, ECF and $\mathrm{ECF}_{\mathrm{r}}$ were significantly different from OCF $(F=873.77$, df $=2$, $\mathrm{p}<0.01$ and $F=4344.00, \mathrm{df}=2, \mathrm{p}<0.01$, respectively).

\section{Definition of relevant re-sighting periods}

From 1995 to 2003, re-sighting periods were estimated for each year using Test 2.CT and $N(0,1)$ statistics. A re-sighting period of $9 \mathrm{~d}$ was clearly evident in 1995, 1996, 1998, 1999, 2001 and 2002 (Fig. 4). However, the duration between 2 successive clutches seems variable with years, as $8 \mathrm{~d}$ periods were selected in 2003 and $10 \mathrm{~d}$ periods in 2000.

\section{Estimation of TCF}

Models with time dependent local survival rate were selected for all years (Table 2). In 1998, a model with constant local survival rate competed with a model with time-dependent local survival rate (i.e. $\Delta \mathrm{AIC}<2$ ). 


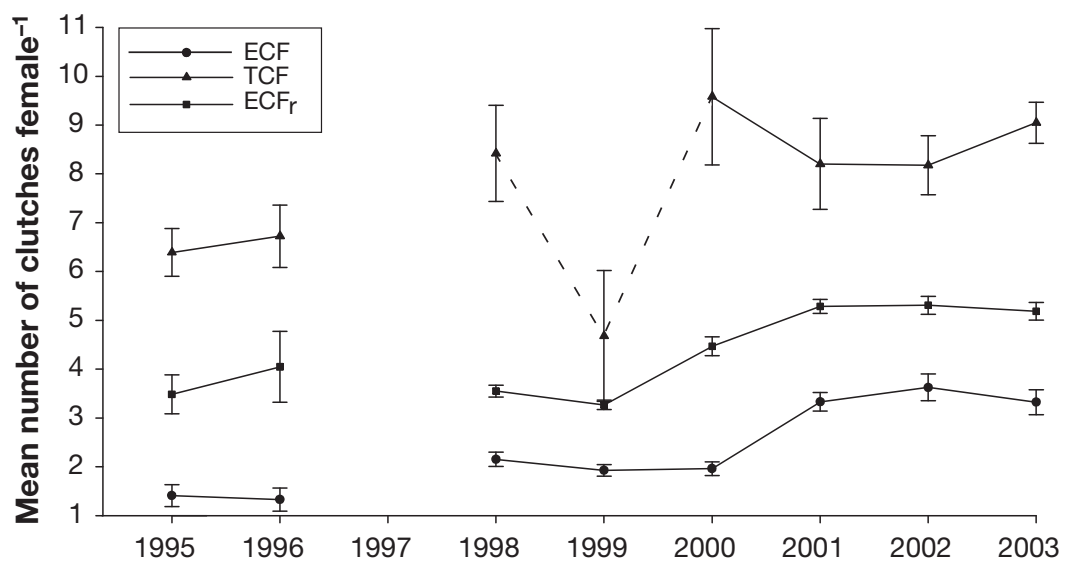

Fig. 3. Dermochelys coriacea. Estimated Clutch Frequency (ECF; circles), Estimated Clutch Frequency on females seen more than once (ECF $F_{r}$ squares), mean Total Clutch Frequency estimated from stopover duration ( $\mathrm{TCF}$; triangles) and $95 \%$ confidence intervals (error bars) of leatherback turtles nesting in

Awa:la-Ya:lima:po (French Guiana) from 1995 to 2003 (1997 excluded)

However, LR testing rejected constancy of local survival rate. Local seniority rates were time-dependent for all years except 1998 and 2000, where seniority was constant over time (Re-sighting rates were selected as time-dependent for all years in local survival models (Table 2) (Table 2, Fig. 5). Re-sighting rates in seniority modelling were selected as time-dependent in all years except 1998 and 2000 (Table 2).

The mean clutch frequency derived directly from the total stopover duration (i.e. TCF) gave values from 4.57 $(\mathrm{SE}=0.12)$ in 1999 to $9.58(\mathrm{SE}=0.13)$ in 2003 (Fig. 3). The inter-annual variations in TCF were highly significant (repeated measures ANOVA: $F=$
73.88, df $=64, \mathrm{p}<0.01$ ) when all years were considered (i.e. from 1995 to 2003). The stopover durations estimated in 1999 were very different from the other years, in both amplitude and shape. However, a closer analysis of data collected during this year showed that CR protocol had not been carried out for 2 periods of 6 and 9 successive days in the middle of the season (21-26 June and 28 June-6 July, respectively). The relatively low TCF estimated in this season might originate from this gap in CR protocol. Because this low value might have a big influence on temporal variations, we performed the same analysis excluding 1999. In this latter anlysis, TCF remained highly variable between years (repeated measures ANOVA: $F=75.42, \mathrm{df}=56, \mathrm{p}<0.01)$.

\section{DISCUSSION}

The use of relative population size indices based on animal activity assumes that a direct relationship exists between the population size and the monitored index (Seber 1982, Schwarz \& Seber 1999). If the proportionality factor varies over years, it is impossible to estimate temporal trends in population size, unless the proportionality factor is accurately estimated. In marine turtles, the total number of clutches laid in a particular season is commonly used as an index of

Table 2. Dermochelys coriacea. Survival and recruitment probability model selection based on $\Delta$ AICc. The best model has the lowest AICc (i.e. $\triangle \mathrm{AICC}=0$; bold face). $S$ : survival probability, $\gamma$ : recruitment probability, $p$ : re-sighting probability. Subscripts $t$, $\tau$ and '.' stand for time variations, transient effect and constancy, respectively

\begin{tabular}{|c|c|c|c|c|c|c|c|}
\hline \multirow[t]{2}{*}{ Year } & \multirow{2}{*}{$\begin{array}{l}\text { Re-sighting } \\
\text { probability }\end{array}$} & \multicolumn{3}{|c|}{ Local survival modeling } & \multicolumn{3}{|c|}{ Local seniority modeling } \\
\hline & & $S_{\tau}$ & $S_{\tau+t}$ & $S_{\tau \times t}$ & $\gamma_{\tau}$ & $\gamma_{\tau+t}$ & $\gamma_{\tau \times t}$ \\
\hline \multirow[t]{2}{*}{1995} & $p$. & 139.701 & 0.693 & 0.000 & 140.582 & 6.780 & 0.000 \\
\hline & $p_{t}$ & 10.936 & 6.205 & 10.701 & 24.985 & 22.070 & 24.263 \\
\hline \multirow[t]{2}{*}{1996} & $p$. & 167.870 & 0.000 & 1.797 & 335.453 & 4.470 & 0.000 \\
\hline & $p_{t}$ & 56.700 & 2.673 & 5.081 & 32.343 & 5.810 & 16.537 \\
\hline \multirow[t]{2}{*}{1998} & $p$ & 198.262 & 6.383 & 10.964 & 462.341 & 12.286 & 10.979 \\
\hline & $p_{t}$ & 1.370 & 0.000 & 7.591 & 0.000 & 1.202 & 10.979 \\
\hline \multirow[t]{2}{*}{1999} & $p$. & 140.415 & 0.000 & 15.302 & 233.635 & 12.523 & 17.973 \\
\hline & $p_{t}$ & 29.227 & 4.388 & 14.495 & 72.371 & 0.000 & 5.262 \\
\hline \multirow[t]{2}{*}{2000} & $p$ & 442.543 & 182.774 & 135.541 & 495.236 & 156.764 & 139.275 \\
\hline & $p_{t}$ & 36.400 & 0.000 & 8.729 & 0.000 & 9.758 & 23.898 \\
\hline \multirow[t]{2}{*}{2001} & $p$ & 442.543 & 184.663 & 135.541 & 602.652 & 93.928 & 73.287 \\
\hline & $p_{t}$ & 36.400 & 0.000 & 8.729 & 101.631 & 0.000 & 3.166 \\
\hline \multirow[t]{2}{*}{2002} & $p$ & 442.543 & 184.663 & 135.541 & 391.656 & 8.356 & 17.388 \\
\hline & $p_{t}$ & 36.400 & 0.000 & 8.729 & 185.503 & 0.000 & 6.405 \\
\hline \multirow[t]{2}{*}{2003} & $p$ & 315.403 & 10.082 & 15.494 & 278.014 & 9.686 & 18.411 \\
\hline & $p_{t}$ & 49.619 & 0.000 & 3.954 & 24.064 & 7.498 & 0.000 \\
\hline
\end{tabular}


Fig. 4. Dermochelys coriacea. Definition of re-sighting periods in female leatherbacks nesting in French Guiana from 1995 to 2003 (1997 excluded). In order to apply $\mathrm{CR}$ models, daily CR observations need to be pooled into adequate resighting periods, within which a female is observed once. Adequate re-sighting periods were annually assessed using $\mathrm{N}(0,1)$ statistics and Test 2.CT (Pradel 1993). Vertical bars represent $\mathrm{N}(0,1)$ statistics: grey, trap-shyness (i.e. $\mathrm{N}(0,1)>0$ ) and black, trap-happiness (i.e. $\mathrm{N}(0,1)<0)$. Triangles correspond to Test 2.CT P value (Pradel 1993). Dashed line: p-level $=0.05$. The relevant re-sighting periods are indicated by vertical bold arrows: Test 2.CT (p-level > 0.05) and the absolute value of $N(0,1) \approx 0$
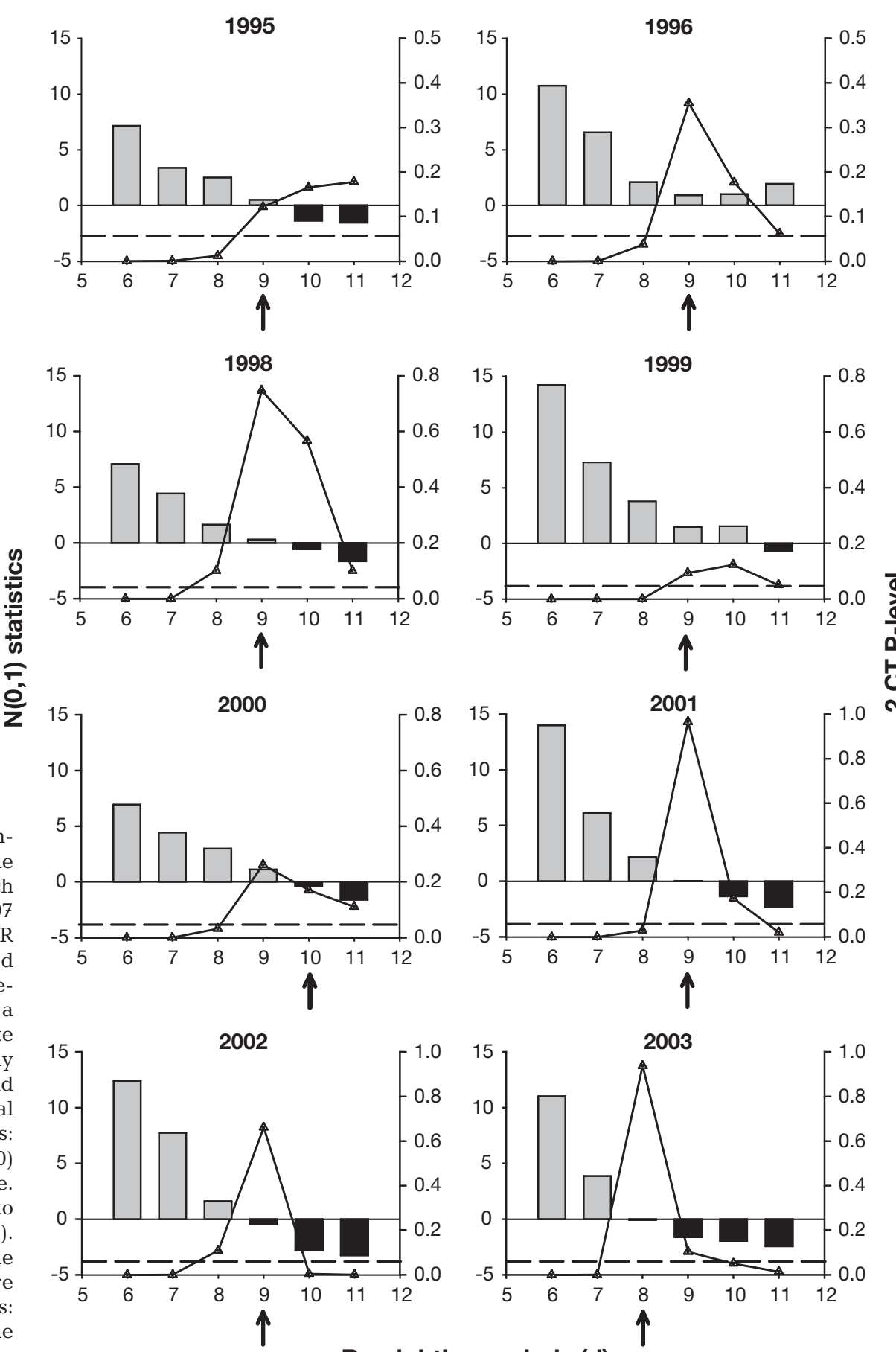

\section{$\frac{\bar{d}}{\frac{\sigma}{1}}$}

nesting population size (Schroeder \& Murphy 1999). In this case, the proportionality factor is the number of clutches laid female ${ }^{-1} \mathrm{yr}^{-1}$, also called clutch frequency.

By using stopover duration to assess the true clutch frequency, we assumed that females do not nest outside the sampling season. Although Schaub et al.'s (2001) method estimates the time an animal has spent in the nesting area before the first and after the last observations, this corrective method is constrained by the start and the end of the CR survey. Since Schaub's (2001) method relies on CR data, stopover duration cannot exceed the total duration of annual surveys. The main nesting season for leatherback turtles in French Guiana extends on average from early March to mid-August (Fretey \& Girondot 1989, Girondot \& Fretey 1996). Although nest counts have been temporally and spatially heterogeneous on Awa:la- 

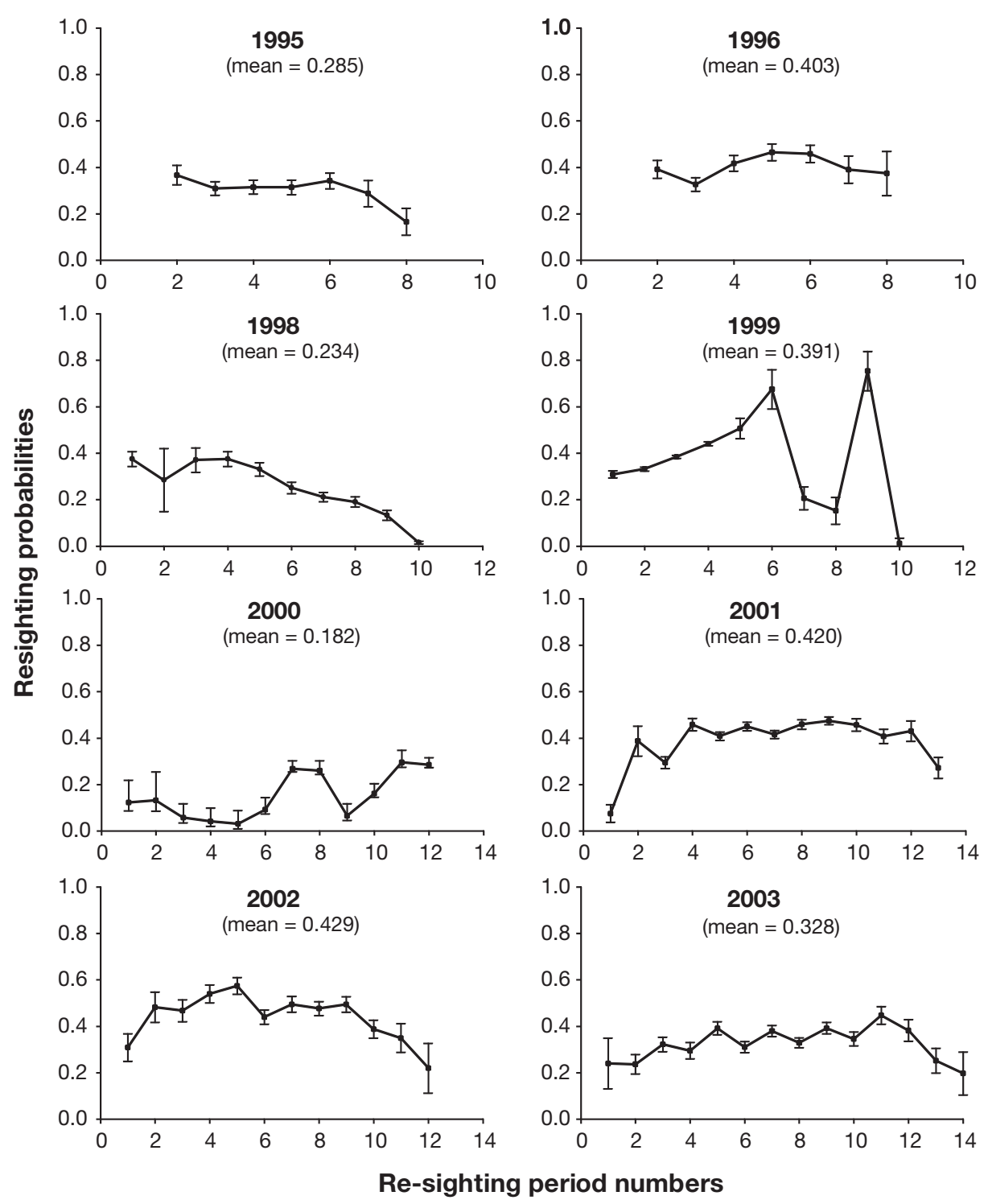

Fig. 5. Dermochelys coriacea. Estimated re-sighting probabilities (squares) and 95\% confidence intervals (error bars) of leatherback turtles nesting in Awa:la-Ya:lima:po (French Guiana) from 1995 to 2003 (1997 excluded). Estimation of re-sighting probabilities was derived from model selection (see Table 2)

Ya:lima:po beach, modelling the nesting season has been possible for some years (i.e. 1986, 1987, 1991, 1993, 1994, 1998, 2000-2003; Rivalan 2004). Based on these data, it appears that the nesting season is seasonally variable. The beginning of the nesting season, defined as the point where $10 \%$ of the peak number of nests per night was reached $\left(\mathrm{D}_{10 \%}\right)$, was observed on varying dates between March 20 and May 15 (Rivalan 2004). Individual tagging was generally begun before $\mathrm{D}_{10 \%}$, except in 2001 and 2003, where it begun respectively 8 and $12 \mathrm{~d}$ after $\mathrm{D}_{10 \%}$. This implies that TCF is probably an under-estimated true clutch frequency for those years, but it is hard to quantify the amplitude of this bias.

A more critical assumption was that adult females come onto the beach to nest once per time-adjusted period. CR data analysis with Test 2.CT-selected resighting periods ranged from 8 to $10 \mathrm{~d}$, depending on the season in question. Based on physiological data, minimal duration between 2 successive clutches in sea turtles was estimated to 6 d (Owens 1980). Intensive beach monitoring performed at Awa:laYa:lima:po in 1988 validates this assumption, since females were found to come ashore for nesting every $9.8 \mathrm{~d}$ on average (Fretey \& Girondot 1989). Based on data collected on St. Croix (US Virgin Islands) from 1982 to 1994, inter-nesting interval in leatherbacks was estimated to $9.6 \mathrm{~d}$ (Boulon et al. 1996). Therefore, it seems reasonable to assume that a female nests only 1 clutch within a period of 8 to $10 \mathrm{~d}$. The internesting interval (i.e. duration between 2 successive clutches within a season) is negatively correlated with sea surface temperature (SST; Sato et al. 1998). The range of inter-nesting interval assessed by Test 2.CT might therefore originate from variations in the mean annual SST. 
Using a mean re-sighting period to approximate inter-nesting periods might introduce bias in stopover duration if a nesting population is composed of 2 groups of females. Since leatherbacks are ectotherms, if a group of nesting females swims in colder water, their mean inter-nesting interval will likely be longer than females swimming in warmer water. The resulting stopover duration will be underestimated if the 2 groups are pooled. A second source of bias in our estimation of clutch frequency is the neglect of possible intra-seasonal skipping. On those 2 particular issues, ECF is probably less biased, because it is based on an individual assessment of an intervening clutch between 2 observed clutches (Frazer \& Richardson 1985, Johnson \& Ehrhart 1996).

Clutch frequency estimated from stopover duration (TCF) was considerably larger than clutch frequency estimated from ECF. Several explanations can explain the discrepancy between these 2 estimators. First, the fundamental weakness of ECF is that it neglects the time spent before the first and after the last observations. Since Schaub et al.'s (2001) method was specifically developed to remedy this bias, it is not surprising that TCF is larger than ECF. However, Efford (2005) showed that Schaub et al's (2001) method might overestimate true stopover under particular conditions. Assuming that an animal that has already stopped over for several days has the probability of departure as a newly-arrived animal (i.e. stopover duration follow a Poisson distribution), simulations showed that estimates of mean stopover duration were inflated by $100 \%$ (Efford 2005). Sea turtles are considered capital breeders, i.e. energy invested in reproduction is gathered prior to reproduction. It is therefore unlikely that a female already present on nesting grounds, who has already drawn on her energy reserves to nest, will have the same probability of departure as a female who has just arrived from the feeding grounds. Our case study corresponds to Schaub et al.'s (2001) initial situation where most animals spend approximately the same time at the stopover site. In this case, stopover estimation performs well (Pradel et al. 2005). Secondly, Johnson \& Ehrhart (1996) and Broderick et al. (2002) found that ECF is an underestimate of true clutch frequency because when a female nests only once, no correction is possible. We acknowledged that one-time nesters are of major importance in the ECF of leatherbacks nesting in French Guiana since they represent about $50 \%$ of females observed every year. Even when one-time nesters were discarded from the analysis, ECF remained lower than TCF. Unlike other sea turtles, which exhibit a more constant nesting fidelity (Bosc \& Le Gall 1986), field observations of leatherbacks have shown that fidelity may be relaxed in this species, allowing occasional excursions to neighbouring beaches in Suriname (Hilterman \& Goverse 2003). These animals, referred to as transients, might explain the large proportion of females observed only once. In our computation of stopover, emigration and immigration probabilities were estimated after suppression of the first observation of all animals. This method, proposed by Pradel et al. (1997), is a reliable method for correcting bias of transients in the estimation of demographic parameters. Since stopover resulted from immigration and emigration probabilities, our estimators of clutch frequency derived from stopover duration are expected to be less affected by one-time nesters than ECF. However, our modelling did not account for non-resident females observed more than once on Awa:la-Ya:lima:po beach. Predicting the direction of the bias associated with those non-resident females is challenging, since it depends on patterns of beach shifting. Indeed, if non-resident females nest successively on Awa:la-Ya:lima:po beach and then go back to their beach, they will increase probability of departure. Considering residents and non-residents as a pool will induce an over-estimation of the mean departure probability and subsequently induce under estimations of stopover duration. Conversely, if non-resident females nest once at the beginning of nesting season and once at the end of the nesting season, stopover duration will be overestimated. However, this bias is not inherent to TCF, since ECF is affected in the exact same way.

Sandy Point Wildlife Refuge (St. Croix, US Virgin Islands) has been the focus of beach monitoring for leatherbacks in the Atlantic since the early 1980s (Boulon et al. 1996). The very high re-sighting probability estimated on Sandy Point (i.e. 0.92; SE = 0.005, Dutton et al. 2005) is a good reason for questioning the relevance of clutch frequency derived from stopover. On Sandy Point, OCF was 5.26 nests female ${ }^{-1} \mathrm{yr}^{-1}$ (range $=3.90$ to $6.03, \mathrm{SE}=0.73$, Boulon et al. 1996) . Boulon et al. acknowledged, notably, that OCF may under-estimate annual nesting because females may also nest unobserved on other beaches (Boulon et al. 1996). Our estimations of clutch frequency were between 4.68 and 9.04. Although females nesting in Sandy Point do not belong to the same population as females nesting in French Guiana (Dutton et al. 1999, 2003), we were confident that the estimators of clutch frequency derived from stopover duration are sufficiently plausible.

As a direct consequence of discrepancy in clutch frequency estimators, the total number of nesting females in Awa:la-Ya:lima:po (estimated by dividing the total number of nests by clutch frequency estimator) was smaller with TCF than ECF. Based on the estimation of total number of nests in the region from 
1995 to 2002 (Girondot et al. 2002), the number of nesting females ranged from 790 to 4542 (TCF) to 2750 to 21800 (ECF). Although these 2 estimates overlapped, relying on ECF might overestimate nesting population size derived from nest counts. Given the critically endangered status of the leatherback sea turtle (Hilton-Taylor et al. 2002), and that French Guiana is one of the largest remaining nesting grounds for this species (Spotila et al. 1996), conservation actions which have already been started in French Guiana must be continued. More generally, given the weakness of ECF, conservation policies relying on ECF might need to be reconsidered in nesting grounds where sampling effort is low and variable. However, relying on the number of nesting females to assess the status of a population presents a caveat (Bjorndal et al. 1999, 2000a, Heppell et al. 2005, Troëng \& Rankin 2005). Environmental variables are known to influence the number of turtles ready to nest in a given year (Limpus \& Nicholls 1988, Bjorndal et al. 1999, 2000a, Troëng \& Rankin 2005). For instance, the low number of females estimated in 1998 might reflect a low probability of breeding for that year. This statement is confirmed by the larger numbers of females estimated in the most recent years (i.e. about 1200 females from 1999 to 2002). Capture-recapture models enable estimation of the probability of being a breeder in a given year (OpenRobust design; Kendall \& Bjorkland 2001). Dutton et al. (2005) used this method and showed a significant increase in female leatherback populations nesting in Sandy Point (St Croix, US Virgin Islands) from 1982 to 2001. However, Open Robust Design methodology is not yet applicable to leatherbacks nesting in French Guiana, notably because of the high proportion of females nesting once within and between seasons (Kendall \& Bjorkland 2001, Rivalan et al. in press). In this context, using the total number of nests remains a valuable tool for conservation purposes and the present study confirms the need to conduct nest counts and capture-recapture monitoring simultaneously in sea turtle conservation programs.

Acknowledgements. We are indebted to everyone who participated in the Kawana project in French Guiana. We also thank the authorities and inhabitants of Awa:la and Ya:lima:po villages for their active participation in the marine turtle study and conservation program. The tag database used for this study is the result of a joint effort of the organizations involved in sea turtle conservation in French Guiana (Direction Régionale de l'Environnement, Greenpeace, Kulalashi, Kwata, ONCFS, Sépanguy, WWF) and in Suriname (Biotopic, STINASU, WWF). We thank V. Delmas and J.-S. Lauzon-Guay for guidance with statistical analyses. The manuscript was improved using comments from M. Wong, J. Chevalier, W. Kendall and 3 anonymous reviewers.

\section{LITERATURE CITED}

Akaike H (1974) A new look at the statistical model identification. IEEE Trans Automat Control 19:716-723

Allard MW, Miyamoto MM, Bjorndal KA, Bolten AB, Bowen BW (1994) Support for natal homing in green turtles from mitochondrial DNA sequences. Copeia 1:34-41

Altrichter M, Boaglio GI (2004) Distribution and relative abundance of peccaries in the Argentine Chaco: associations with humans. Biol Conserv 116:217-225

Becker EF, Spindler MA, Osborne TO (1998) A population estimator based on a network sampling of tracks in the snow. J Wildl Manag 62:698-977

Bjorndal KA, Bolten AB, Lagueux CJ, Chaves A (1996) Probability of tag loss in green turtles nesting at Tortuguero, Costa Rica. J Herpetol 30:567-571

Bjorndal KA, Wetherall JA, Bolten AB, Mortimer JA (1999) Twenty-six years of green turtle nesting at Tortuguero, Costa Rica: an encouraging trend. Conserv Biol 13: 126-134

Bjorndal KA, Bolten AB, Martins HR (2000a) Somatic growth model of juvenile loggerhead sea turtles Caretta caretta: duration of pelagic stage. Mar Ecol Prog Ser 202:265-272

Bosc P, Le Gall JY (1986) Attachement spatial des tortues vertes Chelonia mydas aux plages de l'île de Tromelin (Océan Indien). Oceanol Acta 9:489-495

Boulon RH, Dutton PH, McDonald DL (1996) Leatherback turtles (Dermochelys coriacea) on St. Croix, US Virgin Islands: fifteen years of conservation. Chelonian Conserv Biol 2:141-147

Broderick AC, Glen F, Godley BJ, Hays GC (2002) Estimating the number of green and loggerhead turtles nesting annually in the Mediterranean. Oryx 36:1-9

Choquet R, Reboulet AM, Pradel R, Gimenez O, Lebreton JD (2000) Estimation of stopover duration by bootstrapping: user instruction for the program. CEFE/CNRS, Montpellier

Dutton DL, Dutton PH, Chaloupka M, Boulon RH (2005) Increase of a Caribbean leatherback turtle Dermochelys coriacea nesting population linked to long-term nest protection. Biol Conserv 126

Dutton P, McDonald D (1994) Use of Pit tags to identify adult leatherbacks. Mar Turtle Newsl 67:13-14

Dutton PH, Bowen BW, Owens DW, Barragan A, Davies SK (1999) Global phylogeography of the leatherback turtle (Dermochelys coriacea). J Zool 247:1-13

Dutton PH, Roden S, Galver LM, Hughes G (2003) Genetic population structure of leatherbacks in the Atlantic elucidated by microsatellite markers. In: Seminoff JA (ed) Proceedings of the 22nd International Symposium on Sea Turtle Biology and Conservation. US Department of Commerce, NOAA Technical Memorandum NMFS-SEFSC503, p 44-45

Efford MG (2005) Migrating birds stop over longer than usually thought: Comment. Ecology 86:3415-3418

Ferraroli S, Eckert S, Chevalier J, Girondot M, Kelle L, Maho YL (2002) Marine behavior of leatherback turtles nesting in French Guiana for conservation strategy. In: Mosier A, Foley A, Brost B (eds) Proceedings of the 20th International Symposium on Sea Turtle Biology and Conservation. US Department of Commerce, NOAA Technical Memorandum NMFS-SEFSC-477, Orlando, FL, p 283-285

Frazer NB, Richardson JI (1985) Annual variation in clutch size and frequency for loggerhead turtles, Caretta caretta, nesting at Little Cumberland Island, Georgia, USA. Herpetologica 41:246-251

Frazer NB, Richardson JI (1986) The relationship of clutch 
size and frequency to body size in loggerhead turtles, Caretta caretta. J Herpetol 20:81-84

Fretey J, Girondot M (1989) L'activité de ponte de la tortue luth, Dermochelys coriacea (Vandelli, 1761), pendant la saison 1988 en Guyane française. Rev Ecol (Terre Vie) 44: 261-274

Gerrodette T, Talylor BL (1999) Estimating population size. In: Eckert KL, Bjorndal FA, Abreu-Grobois FA, Donnelly M (eds) Research and management techniques for conservation of sea turtles, Vol 4. Marine Turtle Specialist Group publication, p 67-71

Girondot M, Fretey J (1996) Leatherback turtles, Dermochelys coriacea, nesting in French Guiana, 1978-1995. Chelonian Conserv Biol 2:204-208

Girondot M, Tucker AD, Rivalan P, Godfrey M, Chevalier J (2002) Density-dependent nest destruction and population decline of Guianan leatherback turtles. Anim Conserv 5: 75-84

Godley BJ, Broderick AC, Moraghan S (1999) Short-term effectiveness of Passive Integrated Transponder (PIT) tags used in the study of Mediterranean marine turtles. Chelonian Conserv Biol 3:477-479

Hays G, Houghton JDR, Myers AE (2004) Pan-Atlantic leatherback turtle movements. Nature 429:522

Heppell SS, Crouse DT, Crowder LB, Epperly S, Gabriel W, Henwood T, Márquez R, Thompson NB (2005) A population model to estimate recovery time, population size, and management impacts on Kemp's ridley sea turtles. Chelonian Conserv Biol 4:767-773

Hilterman ML, Goverse E (2003) Aspects of nesting and success of the leatherback turtles (Dermochelys coriacea) in Suriname, 2002. World Wildlife Fund Guianas/Bio Foundation, Amsterdam

Hilton-Taylor C, Sarti Martinez AL, Crouse D, Abreu A (2002) 2000 IUCN Red List of threatened species - Dermochelys coriacea. IUCN, Gland, Switzerland

James MC (2000) Distribution and conservation of the leatherback (Dermochelys coriacea) in Atlantic Canada: research partnerships with the fishing community. In: Kalb HJ, Wibbels T (eds) Proceedings of the 19th International Symposium on Sea Turtle Biology and Conservation. US Department of Commerce, NOAA Technical Memorandum NMFS-SEFSC-443, South Podre Island, TX, p 52

James MC, Herman TB (2001) Feeding of Dermochelys coriacea on medusae in Northern Atlantic. Chelonian Conserv Biol 4:202-205

Johnson SA, Ehrhart LM (1996) Reproductive ecology of the Florida green turtle: clutch frequency. J Herpetol 30 : 407-410

Kendall WL, Bjorkland R (2001) Using Pollock's robust design to estimate temporary emigration from capture-recapture data, without assuming closure within periods. Biometrics $57: 1113-1122$

Lebreton JD, Burnham KP, Clobert J, Anderson DR (1992) Modeling survival and testing biological hypotheses using marked animals: a unified approach with case studies. Ecol Monograph 62:67-188

Limpus CJ (1992) Estimation of tag loss in marine turtle research. Wildl Res 19:457-469

Limpus CJ, Nicholls N (1988) The southern oscillation regulates the annual numbers of green turtles (Chelonia mydas) breeding around Northern Australia. Aust J Wildl Res 15:157-161

McDonald DL, Dutton PH (1996) Use of PIT tags and photoidentification to revise remigration estimates of leatherback turtles (Dermochelys coriacea) nesting in St. Croix,
US Virigin Islands, 1979-1985. Chelonian Conserv Biol 2: 148-152

Miller JD (1996) Reproduction in sea turtles. In: Lutz PL, Musick JA (eds) The biology of sea turtles. CRC Press, Boca Raton, FL, p 52-71

Owens DW (1980) The comparative reproductive physiology of sea turtles. Am Zool 20:549-563

Parmenter C (1993) A preliminary evaluation of the performance of passive integrated transponders and metal tags in a population study of the flatback sea turtle, Natator depressus. Wildl Res 20:375-381

Pradel R (1993) Flexibility in survival analysis from recapture data: handling trap-dependence. In: Lebreton JD, North PM (eds) Study of bird population. Birkhäuser- Verlag, Basel, p 29-37

Pradel R (1996) Utilization of capture-mark-recapture for the study of recruitment and population growth rate. Biometrics 52:703-709

Pradel R, Hines JE, Lebreton JD, Nichols JD (1997) Capturerecapture survival models taking account of transients. Biometrics 53:60-72

Pradel R, Schaub M, Jenni L, Lebreton JD (2005) Migrating birds stop over longer than usually thought: Reply. Ecology 86:3418-3419

Rivalan P (2004) La dynamique des populations des tortues luths de Guyane Française: recherche des facteurs impliqués et application à la mise en place de stratégies de conservation. $\mathrm{PhD}$ thesis Paris XI - Orsay

Rivalan $\mathrm{P}$, Godfrey $\mathrm{MH}$, Prévot-Julliard AC, Girondot $\mathrm{M}$ (2005a) Maximum likelihood estimates of tag loss in leatherback sea turtles. J Wildl Manag 69:540-548

Rivalan P, Prévot-Julliard AC, Choquet R, Pradel R, Briane JP, Girondot M (2005b) Trade-off between current reproductive investment and delay to next reproduction in leatherback sea turtle. Oecologia 145(4):564-574

Sato K, Matsuzawa Y, Tanaka H, Bando T, Minamikawa S, Sakamoto W, Naito Y (1998) Internesting intervals for loggerhead turtles, Caretta caretta, and green turtles, Chelonia mydas, are affected by temperature. Can J Zool 76:1651-1662

Schaub M, Pradel R, Jenni L, Lebreton JD (2001) Migrating birds stop over longer than usually thought: an improved capture-recapture analysis. Ecology 82:852-859

Schroeder B, Murphy S (1999) Population surveys (ground and aerial) on nesting beaches. In: Eckert KL, Bjorndal FA, Abreu-Grobois FA, Donnelly M (eds) Research and management techniques for conservation of the sea turtles, Vol 4. IUCN/SSC Marine Turtle Specialist Group publication, Washington, DC, p 45-55

Schwarz CJ, Seber GAF (1999) Estimating animal abundance: review III. Stat Sci 14:427-456

Seber GAF (1982) The estimation of animal abundance and related parameters. Griffin, London

Spotila JR, Dunham AE, Leslie AJ, Steyermark AC, Plotkin PT, Paladino FV (1996) Worldwide population decline of Dermochelys coriacea: Are leatherback turtles going to extinct? Chelonian Conserv Biol 2:209-222

Thompson ID, Davidson IJ, O'Donnell S, Brazeau F (1989) Use of tracks transects to measure the relative occurrence of some boreal mammals in uncut forest and regeneration stands. Can J Zool 67:1816-1823

Troëng S, Rankin E (2005) Long-term conservation efforts contribute to positive green turtle Chelonia mydas nesting trend at Tortuguero, Costa Rica. Biol Conserv 121:111-115

Wilson GJ, Delahay RJ (2000) A review of methods to estimate the abundance of terrestrial carnivores using field signs and observation. Wildl Res 28:151-164

Submitted: June 24, 2005; Accepted: December 14, 2005

Proofs received from author(s): June 20, 2006 